\title{
Pengujian Kualitas Minyak Goreng Berulang Menggunakan Metoda Uji Viskositas dan Perubahan Fisis
}

\author{
Anwar Mujadin ${ }^{1}$, Syafitri Jumianto ${ }^{2}$, Riris Lindiawati Puspitasari ${ }^{2}$ \\ ${ }^{1}$ Program Studi Teknik Elektro, Fakultas Sains dan Teknologi \\ ${ }^{2}$ Program Studi Biologi, Fakultas Sains dan Teknologi \\ Universitas Al Azhar Indonesia, Jl. Sisingamangaraja, Jakarta 12110 \\ Penulis untuk Korespondensi/E-mail: amujadin@uai.ac.id
}

\begin{abstract}
Abstrak - Kualitas produk minyak goreng dari setiap pabrikan memiliki karakteristik yang beragam, tergantung dari bahan dan proses pembuatan. Minyak goreng yang digunakan secara berulang akan meningkatkan asam lemak bebas (kolesterol jahat) yang tidak sehat bila dikosumsi oleh manusia. Pada penelitian ini, minyak goreng dipanaskan bertahap sampai pada titik didih. Hasil pengamatan menunjukan viskositas dan perubahan fisis minyak goreng akan menentukan besaran asam lemak bebas.
\end{abstract}

Abstract - The quality of cooking oil products from each manufacturer has a variety of characteristics, depending on the quality of the cooking oil from the material and manufacturing process. Cooking oil used repeatedly will increase the amount of free fatty acids (bad cholesterol), which is not healthy for human consumption. In this research, cooking oil was heated gradually up to the boiling point. The observation showed physical changes in viscosity and cooking oil will determine the amount of free fatty acids.

Keyword - Cooking oil test using viscosity and physical changes methods.

\section{PENDAHULUAN}

$\mathrm{M}$ inyak goreng yang digunakan secara berulang (jelantah) akan meningkatkan asam lemak bebas (kolesterol jahat) yang tidak baik bagi kesehatan manusia. Selain asam lemak bebas, minyak jelantah terkandung residu dari hasil pemanasan bahan. Minyak goreng berulang yang tidak layak digunakan untuk konsumsi diindikasikan dengan adanya perubahan warna dan bau.

Karakterisasi minyak berulang terhadap asam lemak bebas dapat diuji dari kelarutan, titik cair, polimorphism, titik didih, titik pelunakan, slipping point, shot melting point, bobot jenis, viskositas, indeks bias, titik kekeruhan (turbidity point), titik asap, titik nyala dan titik api [1].

Uji kualitas minyak goreng berulang sebelumnya telah diteliti dengan meninjau parameter viskositas dan indeks bias. Dari penelitian tersebut secara kualitatif ditunjukkan bahwa minyak goreng yang paling baik adalah minyak goreng dengan nilai viskositas dan dan indeks bias yang besar [2].

Untuk menguji perubahan viskositas berikut perubahan fisis minyak goreng diperlukan sebuah prototipe yang mampu mengendalikan temperatur stabil pada titik uji dalam orde waktu yang telah ditentukan.

Dalam penelitian ini telah berhasil dirancang bangun sebuah prototipe alat uji viskositas minyak goreng yang dikendalikan oleh mikrokontroler ATMega8 dan LabView sebagai user interface.

Tujuan penelitian ini adalah untuk menentukan seberapa jauh kualitas suatu minyak goreng yang digunakan secara berulang-ulang sampai pada level tidak layak digunakan (dikonsumsi).

Manfaat penelitian adalah mengetahui hubungan pengaruh temperatur terhadap perubahan fisis 
minyak goreng sebagai bahan acuan menentukan kualitas minyak goreng terhadap dampak kesehatan manusia.

\section{TINJAUAN PUSTAKA}

\section{Pengenalan Minyak Goreng}

Minyak goreng adalah bahan pangan non-esensial dan berfungsi sebagai bahan pangan komplemen. Fungsi minyak goreng sangat penting dalam menciptakan aroma, rasa, warna, dan penambahan nilai gizi termasuk vitamin A dan kalori. Minyak yang biasa digunakan untuk menggoreng adalah minyak yang berasal dari ekstrak tumbuhan atau minyak nabati. Minyak nabati tergolong sebagai minyak yang tidak akan mengeras jika dibiarkan di udara terbuka (non drying oil). Salah satu contoh minyak yang termasuk kedalam kelompok non drying oil adalah minyak kelapa sawit [3].

Selama proses penggorengan, minyak akan mengalami banyak reaksi kimia seperti hidrolisis, oksidasi, isomerasi dan polimerisasi. Reaksi-reaksi ini akan menghasilkan zat-zat yang tidak baik untuk kesehatan serta mempengaruhi mutu makanan yang digoreng baik dari segi cita rasa, penampakan maupun nilai gizinya. Minyak yang digunakan untuk menggoreng dalam waktu lama dan terus dipakai secara berulang akan menghasilkan senyawa trans pada asam lemak yang sering kali dikaitkan dengan berbagai gangguan kesehatan [4].

Suhu minyak pada proses penggorengan normal berkisar antara $163^{\circ} \mathrm{C}-196^{\circ} \mathrm{C}$, tergantung dari jenis makanan yang digoreng. Pemanasan minyak goreng dalam waktu lama dan dengan suhu yang tinggi akan menghasilkan senyawa polimer yang berbentuk padat (residu) dalam minyak dan meningkatkan jumlah asam lemak bebas dalam minyak [4][1].

Penggorengan dengan minyak terbatas dilakukan misalnya pada saat menggoreng telur atau menumis sayuran dengan suhu berkisar $117^{\circ} \mathrm{C}-170^{\circ} \mathrm{C}$. Penggorengan deep frying adalah penggorengan dimana bahan terendam seluruhnya dalam minyak. Perbandingan minyak dan bahan yang baik adalah $8: 1$. Penggorengan dapat dilakukan selama lima kali berturut-turut tanpa harus mengganti, mengurangi maupun menambah jumlah minyak yang digunakan. Suhu minyak pada proses penggorengan deep frying dianjurkan antara $177^{\circ} \mathrm{C}-201^{\circ} \mathrm{C}$ serta tergantung pada jenis makanan yang digoreng. Minyak dan lemak yang digunakan dalam proses ini tidak berbentuk emulsi dan memiliki titik asap pada suhu $260^{\circ} \mathrm{C}$. Suhu titik asap minyak goreng dapat bervariasi tergantung pada jumlah asam lemak bebas dan menurun jika digunakan secara berulang-ulang [5].

\section{Viskositas media fluida}

Setiap benda yang bergerak relatif terhadap benda lain selalu mengalami gesekan (gaya gesek). Sebuah benda yang bergerak di dalam fluida juga mengalami gesekan. Hal ini disebabkan oleh sifat kekentalan (viskositas) fluida tersebut. Koefisien kekentalan suatu fluida (cairan) dapat diperoleh dengan menggunakan percobaaan bola jatuh di dalam fluida.

Pada Gambar 1 diperlihatkan gaya gaya bola dalam fluida [2].

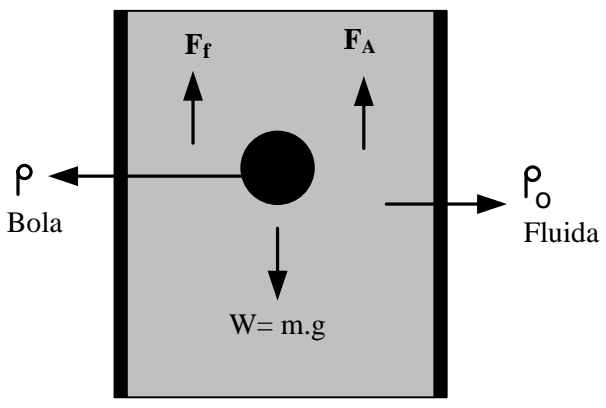

Gambar 1. Gaya-gaya bola dalam fluida [2].

Menurut hukum Newton [2]:

$$
\begin{aligned}
& \sum F=0 \\
& \mathrm{~F}_{\mathrm{A}}+\mathrm{F}_{\mathrm{f}}-\mathrm{W}=0 \\
& \mathrm{~F}_{\mathrm{A}}+\mathrm{F}_{\mathrm{f}}=\mathrm{W} \\
& \mathrm{F}_{\mathrm{f}}=\mathrm{W}-\mathrm{F}_{\mathrm{A}} \\
& 6 \pi+\eta \mathrm{v}=\rho_{\mathrm{b}}-\mathrm{V}_{\mathrm{b}} \cdot \mathrm{g}-\rho_{\mathrm{f}} \cdot \mathrm{g} \cdot \mathrm{V}_{\mathrm{b}} \\
& \eta=\frac{\mathrm{V}_{\mathrm{b}} \cdot \mathrm{g}\left(\rho_{\mathrm{b}}-\rho_{\mathrm{f}}\right)}{6 \pi \mathrm{rv}} \\
& \eta=\frac{4 / 3 \pi \mathrm{r}^{3} \cdot \mathrm{g}\left(\rho_{\mathrm{b}}-\rho_{\mathrm{f}}\right)}{6 \pi \mathrm{rv}} \\
& \eta=\frac{2 / 9 \mathrm{r}^{2} \cdot g\left(\mathrm{~d}_{\text {bola }}-\mathrm{d}_{\text {fluida }}\right)}{\mathrm{v}_{\text {rata-rata }}}
\end{aligned}
$$

Dimana :

$$
\begin{array}{ll}
\eta & =\text { koefisien viskositas fluida } \\
\mathrm{r} & =\text { jari jari bola } \\
\mathrm{g} & =\text { gaya gravitasi } \\
\mathrm{d}_{\text {bola }} & =\text { densitas bola } \\
\mathrm{d}_{\text {fluida }} & =\text { densitas fluida } \\
\mathrm{v}_{\text {rata-rata }} & =\text { rata-rata kecepatan bola jatuh }
\end{array}
$$




\section{Pengaruh Temperatur Terhadap Kecepatan Terminal}

Semakin besar temperatur fluida, maka semakin kecil pula viskositas. Dengan kata lain temperatur fluida berbanding terbalik dengan viskositas. Berdasarkan hukum Stokes, kecepatan terminal (bola jatuh) berbanding terbalik dengan viskositas, dan berbanding lurus dengan temperatur.

Ditunjukkan pula dengan Hukum MaxwellBoltzmann hubungan antara viskositas dan temperatur diformulasikan sebagai [6]:

$$
\eta=A e^{\frac{E_{a}}{R T}}
$$

Dimana:

$$
\begin{aligned}
\eta & =\text { Viskositas } \\
\mathrm{A} & =\text { tetapan cairan } \\
\mathrm{Ea} & =\text { Energi ambang permol } \\
\mathrm{R} & =\text { konstanta Boltzmann } \\
\mathrm{T} & =1.3806488 \times 10-23 \mathrm{~J} /{ }^{\circ} \mathrm{K} \\
& =\text { temperatur (Kelvin) }
\end{aligned}
$$

\section{LabVIEW sebagai User Interface}

LabVIEW merupakan kepanjangan dari Laboratory Virtual Instrument Engineering Workbench, dikembangkan oleh perusahahan besar NI (Nasional Instrumen).

Pada penelitian ini LabView digunakan sebagai user interface pemrosesan dan visualisasi data, terutama untuk menentukan nilai koefisien viskositas dari minyak goreng yang akan diuji. Data parameter seperti diameter bola, massa bola, masa jenis fluida, gravitasi, dan jarak tempuh bola harus dimasukan secara manual kedalam terminal LabView. Waktu tempuh bola jatuh akan dipindai automatis oleh mikrokontroler kemudian diinformasikan ke LabView melalui saluran komunikasi RS232.

\section{METODE PENELITIAN}

Blok diagram uji viskositas dan fisis minyak goreng diperlihatkan pada Gambar 2. Parameter diameter bola, massa bola, masa jenis bola, massa jenis fluida, gravitasi, dan jarak tempuh bola dimasukan secara manual ke dalam terminal LabView. Mikrokontroler (mikon) akan mendeteksi waktu dari lintasan bola. Waktu tempuh bola dipindai dari sensor proximitry A (PA) dan proximitry B (PB), lintasan waktu bola besi dihitung dalam orde $\mu \mathrm{S}$ (mikro detik).

Minyak dipanaskan oleh heater terkendali mikrokontroler (mikon). Saat pemanasan, nilai viskositas diuji tiap kenaikan temperature 25 menit sekali, dengan cara melepaskan bola besi. Setelah terlihat titik didih dan titik asap (panca indra), pengujian viskositas dihentikan berikut dengan mencatat suhu akhir dari titik didih dan titik asap.

Besaran waktu lintasan bola (delay time) setiap pengujian viskositas, dikirim ke user interface LabView melalui saluran serial komunikasi RS232. LabView memproses kecepatan bola dan menghitung nilai viskositas minyak sesuai dengan formulasi (2.1). Data hasil perhitungan viskositas dikumpulkan dan diplot kedalam sebuah grafik. Selanjutnya minyak goreng didinginkan sampai suhu kamar $\left(25^{\circ} \mathrm{C}\right)$. Pengujian diulang lagi dari awal sampai mendapatkan warna dan bau yang berbeda dari minyak goreng awal (murni).

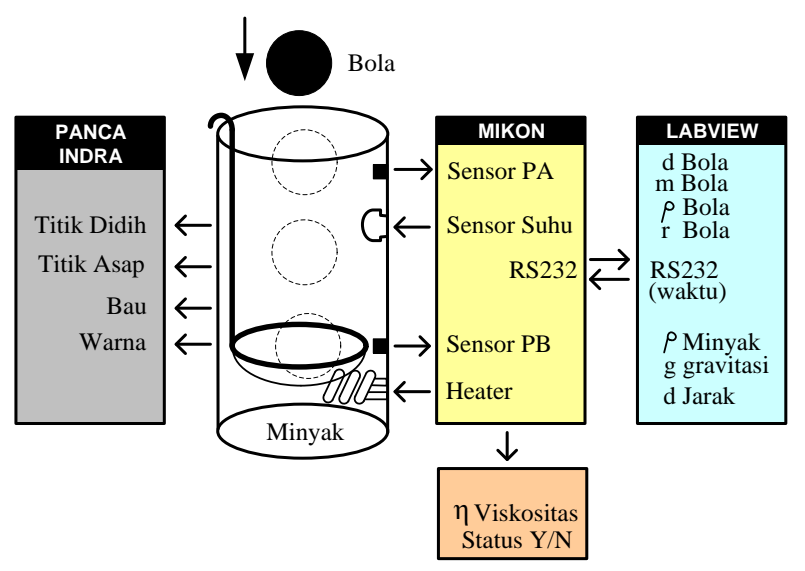

Gambar 2. Blok diagram uji viskositas dan fisis

\section{HASIL DAN PEMBAHASAN}

Hasil rancang bangun prototipe pengujian kualitas minyak goreng diperlihatkan pada Gambar 3 .

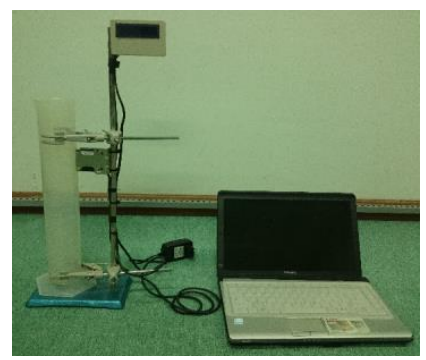

Gambar 3. Hasil rancang bangun prototipe 
Pada Tabel 1 diperlihatkan spesifikasi teknis dan fitur dari prototipe.

Tabel 1. Spesifikasi teknis dan fitur prototipe.

\begin{tabular}{llcc}
\hline \multirow{2}{*}{ No } & Besaran yang Diukur & \multicolumn{2}{c}{ Satuan Ukur } \\
\cline { 3 - 4 } & & Nilai & Satuan \\
\hline 1. & Tegangan Supply Utama & 12.07 & VDC \\
\hline 2. & Tegangan mainboard & 5.03 & VDC \\
\hline & Arus mainboard & 510 & $\mathrm{~mA}$ \\
\hline 3. & Proximitry respon & 25 & $\mathrm{~ms}$ \\
\hline 4. & Tegangan proximitry & 5.03 & VDC \\
\hline 5. & Kosumsi daya Heater & 150 & Watt \\
\hline & Tegangan heater & 220 & VAC \\
\hline 6. & Berat prototipe & 320 & gram \\
\hline 7. & Dimensi prototipe & $150 \times 100 \times 5$ & $\mathrm{~mm}$ \\
\hline
\end{tabular}

Tampilan screenshoot dari perhitungan koefisien viskositas minyak goreng oleh user interface LabView diperlihatkan pada Gambar 4.

\begin{tabular}{|c|c|}
\hline \multicolumn{2}{|c|}{ Koefisien Viskositas Minyak Goreng } \\
\hline 59.8301 & $\mathrm{Ns} / \mathrm{m}^{3}$ \\
\hline Diameter Bola & Jari-jari Bola \\
\hline c) 0.016 & $\sqrt{0.008} \mathrm{~m}$ \\
\hline Massa Bola & Massa Jenis Bola \\
\hline 6) $0.05 \mathrm{~kg}$ & $\longdiv { 2 3 3 0 4 . 3 } \mathrm { kg } / \mathrm { m } ^ { 3 }$ \\
\hline Massa Jenis Fluida & Volume Bola \\
\hline 다요 $\mathrm{kg} / \mathrm{m}^{3}$ & $\longdiv { 2 . 1 4 5 5 2 4 \mathrm { E } - 6 } \mathrm { m } ^ { 3 }$ \\
\hline Gravitasi & Kecepatan Bola \\
\hline t) $9.8 \mathrm{~m} / \mathrm{s}^{2}$ & $0.0522388 \mathrm{~m} / \mathrm{s}$ \\
\hline \multirow{2}{*}{$\begin{array}{l}\text { Jarak Tempuh Bola } \\
\text { c) } 0.35 \mathrm{~m}\end{array}$} & Waktu Tempuh Bola \\
\hline & 6) $6.7 \mathrm{~s}$ \\
\hline
\end{tabular}

Gambar 4. Tampilan screenshoot LabView koefisien viskositas minyak goreng

Dari Gambar 4, parameter yang harus dimasukan kedalam terminal LabView oleh pengguna adalah:
Diameter bola
Massa bola
(0.016 meter),
Jari-jari bola
$(0.05 \mathrm{~kg})$
Massa jenis bola
$(0.08 \mathrm{~m})$
Masa jenis fluida
Gaya gravitasi
$\left(23304.3 \mathrm{~kg} / \mathrm{m}^{3}\right)$
$\left(880 \mathrm{~kg} / \mathrm{m}^{3}\right)$
$\left(9.8 \mathrm{~m} / \mathrm{s}^{2}\right)$
Jarak tempuh bola
$(0.35 \mathrm{~m})$

Parameter yang masuk dari mikrokontroler (mikon) adalah :

Waktu tempuh bola $(6.7 \mathrm{~s})$

Nilai yang diproses kemudian ditampilkan oleh LabView adalah :

$$
\text { Volume bola } \quad\left(2.145524 .10^{-6} \mathrm{~m}^{3}\right)
$$
Kecepatan bola
$(0.0522300 \mathrm{~m} / \mathrm{s})$
Koefisien viskositas $\left(59.8301 \mathrm{Ns} / \mathrm{m}^{3}\right)$

Data hasil pengamatan viskositas dan perubahan fisis minyak goreng berulang diperlihatkan pada Tabel 2.

Tabel 2. Data hasil pengamatan viskositas dan perubahan fisis (4 kali pengujian)

\begin{tabular}{|c|c|c|c|c|c|c|c|c|}
\hline \multirow{2}{*}{$\begin{array}{c}\text { Penguji } \\
\text { an } \\
\text { Viskosit } \\
\text { as } \\
\left(\mathrm{Ns} / \mathrm{m}^{3}\right)\end{array}$} & \multicolumn{7}{|c|}{ Temperature $\left({ }^{\circ} \mathrm{C}\right)$} & \multirow{2}{*}{$\begin{array}{c}\text { Asap } \\
\left({ }^{\circ} \mathrm{C}\right)\end{array}$} \\
\hline & 25 & 50 & 75 & 100 & 125 & 150 & 175 & \\
\hline 1 & 59.8 & 52.6 & 46.3 & 42.5 & 41.5 & 40.2 & 39.5 & 169.5 \\
\hline 2 & 56.9 & 51.5 & 44.3 & 42.0 & 40.8 & 39.5 & 38.7 & 158.5 \\
\hline 3 & 53.1 & 48.5 & 43.2 & 41.5 & 38.3 & 37.8 & 36.8 & 155.3 \\
\hline 4 & 49.8 & 47.5 & 41.9 & 40.8 & 38.1 & 37.5 & 36.5 & 170.1 \\
\hline
\end{tabular}

Pada Gambar 5. Diperlihathan grafik hasil pengamatan viskositas dan perubahan fisis minyak goreng berulang (4 kali uji) sesuai dengan Tabel 2.

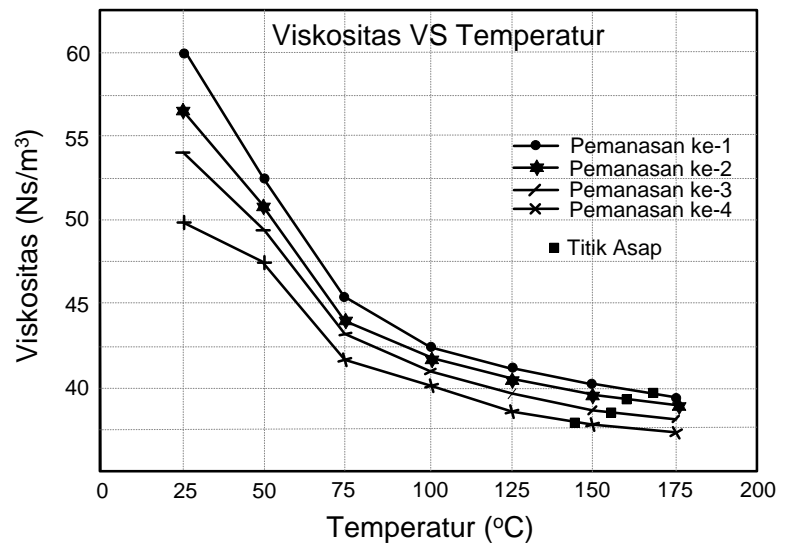

Gambar 5. Grafik hasil pengamatan viskositas dan perubahan fisis minyak goreng berulang (4 kali uji)

\section{KESIMPULAN}

Dari Tabel 2 dan Gambar 5 ditunjukan titik didih minyak goreng rata-rata adalah $175^{\circ} \mathrm{C}$. Suhu titik asap semakin berkurang seiring dengan berulangnya minyak goreng dipanaskan, tiap satu kali pemanasan rata-rata berkurang sebesar $11^{\circ} \mathrm{C}$, artinya kandungan asam lemak bebas meningkat setiap kali pemanasan. Titik asap lebih cepat timbul bila terjadi kenaikan asam lemak bebas yang signifikan. Pengukuran viskositas lebih ideal pada suhu kamar $\left(25^{\circ} \mathrm{C}\right)$ dibandingkan suhu pada titik didih. Pada suhu kamar terjadi perbedaan nilai viskositas rata-rata sebesar $3.75 \mathrm{Ns} / \mathrm{m}^{3}$ sedangkan 
pada titik didih perbedaan nilai viskositas rata-rata sebesar $0.9 \mathrm{Ns} / \mathrm{m}^{3}$.

Penyimpangan ukur viskositas pada titik didih dikarenakan terjadinya pemuaian bola uji karena area panas media, yang menyebabkan parameter masa jenis dan volume bola berubah. Ditunjukan pula, nilai viskositas terus berkurang bila minyak goreng terus digunakan (berulang).

\section{DAFTAR PUSTAKA}

[1] Ketaren, Pengantar Minyak dan Lemak Pangan, UI Press, Jakarta: UI Press, 1986.
[2] A. I. Susan, Alternatif Uji Kualitas Minyak Goreng Berdasarkan Perubahan Sudut Polarisasi Cahaya, Skripsi. Jurusan Fisika FMIPA UNDIP, 2010.

[3] Amang, B, Ekonomi Minyak Goreng di Indonesia, Bogor: IPB Press, 1996.

[4] F.G. Winarno, Minyak Goreng Dalam Menu Masyarakat, Balai Pustaka, 1999.

[5] Silalahi, Asam Lemak Trans dalam Makanan dan Pengaruhnya terhadap Kesehatan, Buletin Teknologi dan Industri Pangan, Vol XIII no.2 Th. 2002.

[6] Istianah, Studi Pengaruh Medan Radio Frekuensi (RF) terhadap Perubahan Sudut Polarisasi pada Minyak Goreng", Skripsi. Jurusan Fisika FMIPA UNDIP, 2008. 